\title{
RELEVANCE OF INDICATORS OF SOCIAL EMOTIONAL HEALTH IN DIFFERENT SAMPLES OF ADOLESCENCE
}

\author{
Laura Čukna \\ University of Latvia, Latvia \\ Guna Svence \\ University of Latvia, Latvia \\ Ieva Pakse \\ University of Latvia, Latvia
}

\begin{abstract}
The aim of this research was to determine whether there are statistically relevant differences in Michael J. Furlong's concept of socio-emotional health with meta construct Covitality (SEV factor) between teenage and youth selections, gender, and nationalities in different schools.

The participants of the research were 593 respondents from Latvia, aged 11-19 years. Out of the total selection of participants $(N=593)$ there were 318 teens $(M=13.01, S D=.84)$, of them 151 boys and 167 girls; the other group of 274 young people $(M=15.85, S D=1.02)$, consisted of 132 males and 142 females. To measure the positive aspects of the mental health, A Socioemotional Health Survey was used (Social Emotional Health Survey - Secondary, SEHS-S, Furlong, You, Renshaw, \& O'Malley; 2014; adapted in Latvian by Knaze, 2017).

There were raised 6 questions in the beginning of the research. Results showed higher results for girls on the scale Belief in Others (its substructure Peer Support) and on the scale Emotional Competence (its substructure Empathy), compared to the selection of boys.

The results on the scale Engaged living were statistically higher for teens compared to the selection of the youth. Teens also had higher statistical results of Co-vitality compared to the youth. However, the selection of youth showed statistically higher results in the Emotion Regulation (the substructure of Emotional Competence) compared to the selection of teens.

The respondents from city schools showed statistically higher results on the scale Belief in Self, Engaged Living and Co-vitality compared to students from town schools.

The Regression Analysis highlights the importance of the school environment in Co-vitality, which explains the 3\% variance of the socio-emotional health.
\end{abstract}

Keywords: Socio-emotional health, teenagers, youth, city, town, nationalities, gender.

\section{Introduction}

The World Health Organization (WHO) has stated that there is no health without mental health. Mental health is a complete state physical, mental, and social well- being. Various international organizations, such as The European 
Čukna et al., 2021. Relevance of Indicators of Social Emotional Health in Different Samples of Adolescence

Commission or The World Health Organization, are committed to promoting the mental health of adolescents (Piquers et al., 2017). Positive development of social and emotional health promotes positive and meaningful communication with other people, develops the emotional sphere increases self-esteem and a sense of self-efficacy (Belkin et al., 2017).

All over the world and in Latvia also, more and more often children of different nationalities, as well as children from different social groups study in schools together. Studies show that socio-economics difficulties predict lower socio-emotional functioning of children. As well as children who have started a new school where classes are taught in a language other their mother tongue, the pupil faces a language barrier. This situation can make it difficult to learn new social skills with peers (Thomson et al., 2017).

The aim of this research was to determine whether there are statistically relevant differences in Michael J. Furlong's concept of socio-emotional health with meta construct Covitality (SEV factor) between teenage and youth selections, gender, and nationalities in different schools.

Understanding the emotional health patterns of adolescents and young people at school can help counselors, teachers, parents, and health professionals identify potential problems and help young people find solutions. This knowledge would help psychologists and other practitioners to develop programs to help young people and their families understand the problems faced by students in rural schools and the difficulties faced by students in urban schools. Understanding socio-emotional issues would allow to predict and to identify difficulties faced by young people in different environments (Wang et al., 2018). The concept of socioemotional health has been studied in Latvia since 2016. In Latvia M.J. Furlong's social and emotional health survey is adapted (LU, Timofejeva, 2014; Knaze, 2015; Pētersone, 2018; Čukna, 2019; Cāzere-Pakalna, 2019), in mentioned studies there have been determined whether there are statistically significant correlations and differences between school anxiety, bullying and socioemotional health of adolescents and young people, and examined the resilience and strengths intervention program, analyzing whether socio-emotional health indicators are changing (Putnina, 2017). The environment in which the child lives, such as the pupil's social status and the socio-economic status of the peers, is linked to the mental and emotional health of the children and adolescents (Wang et al., 2018). The problem today is that teachers often lack the knowledge and skills to respond effectively to student behavior that may seem disruptive. The way the teacher responds to the student who is overwhelmed by intense emotions can affect a child's ability to develop self-control skills. Studies show that lack of knowledge on this issue can lead to an endless cycle in which the child initially expresses disruptive behaviors resulting from emotional experiences, followed by the teacher's negative attitude towards the child, which creates tension in the 
teacher-child relationship. The teacher develops a negative attitude towards the child, because of which the teacher further begins to react negatively to the child by threatening penalties. Such behavior promotes more and more emotional experiences in the student, which promotes the repetition of the cycle with the student's disruptive behavior (Bratton et al., 2019).

\section{The Concept of Socio-emotional Health for Adolescents and Young People at School}

Study of socio-emotional health is based on the model of positive psychology, on the research of developmental resources among young people, that promotes healthy and positive development. Concepts that promote youth development include a sense of self-efficacy, gaining social support from others, emotional competence that includes empathy and emotional regulation, and components such as optimism and gratitude (Felix et al., 2019). M. J. Furlong and his team conducted a study in which analyzed adolescents in the United States and found that $15-20 \%$ of young people have problems with social and emotional health. Studies shows that in adolescence there is a rapid progress in personality development, which is related to the adolescent's internal and external resources (Furlong et al., 2014). This group of researchers based on the assumption that the successful development of adolescents' socio-emotional health is ensured by the young person's life's conditions, which promote the development of internal psychological norms related to belief in self, belief in others, emotional competence, viability engaged living. Nowadays studies show that socioemotional health is related with marital status, financial status, the environment in which the student is located, and academic achievements (Renshaw et al., 2014).

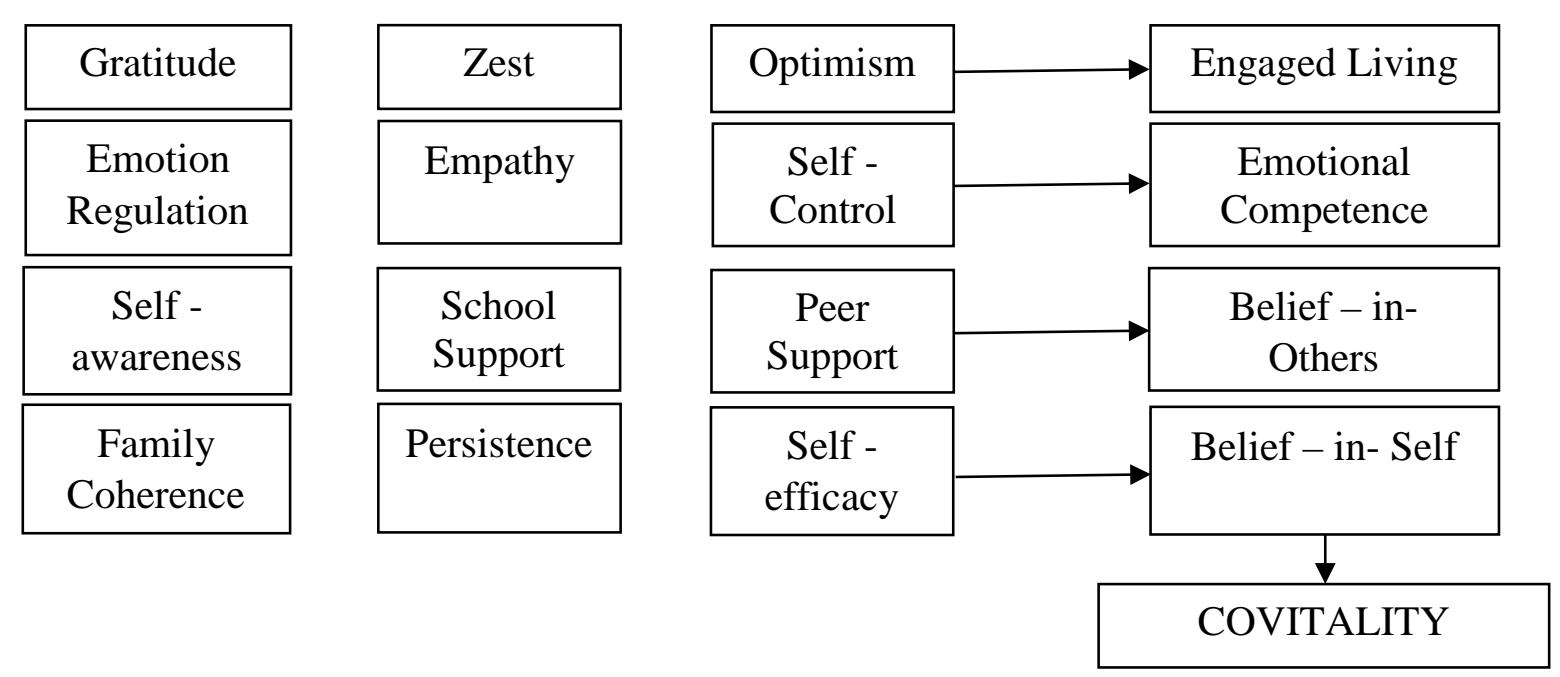

Figure 1 SEHS-Secondary Higher-order Covitality Model (Furlong, 2014) 
Čukna et al., 2021. Relevance of Indicators of Social Emotional Health in Different Samples of Adolescence

M. J. Furlong's model of socio-emotional health is based on a range of social and emotional skills related to the positive development of young people (Renshaw et al., 2018). The proposed model of socio-emotional health includes 12 lower order features that form four main constructs, which are called socioemotional health. The model is developed by summarizing studies on adolescent development from perspective of social psychology, the concept of $I$ and cognitive psychology. As a teenager develops and matures, there are more and more extensive cognitive schemes that are used to effectively understand and organize their life experiences (Furlong et al., 2014).

The developed model offers four areas of positive psychology. The first belief in self, consist of three constructs, which are self-efficacy, preservice and self-awareness. The second - trust in others, under which there is family support, school support and peer support. The third area is emotional competence, which consists of three constructs - self-regulation of emotions, empathy, and selfregulation. The fourth area is engaged living, which includes gratitude, enthusiasm or zest and optimism (Furlong at al., 2014).

These four main areas form the highest construct of COVITALITY, which can also be translated as a synergistic interaction of various factors of engaged living or SEH (socio-emotional health) factor. Researches show that by analyzing the overall SEH factor, the understanding of adolescents' and young peoples' quality of life can be analyzed and the success and well-being of adolescent and young people can be predicted both now and in the future (Timofẽjeva, 2014). For example, children, who develop gratitude to others, show optimism about the future and trust others, contribute to their own positive development, it promotes interaction between other people around them who engage in activities that promote their development of socio-emotional health. This model shows that better development results are achieved if several of the proposed constructs are present. Model is based on positive youth development perspective, emphasizing the creation of conditions that teenagers and young adults allow to influence and direct their lives themselves, rather than passively let it run (Renshaw et al., 2018).

\section{Overview of Nowadays Researches on Socio-emotional Health in Psychology}

In a study carried out 2014, socio-emotional health is defined as the ability to regulate and control one's emotions, as the ability and emotional intelligence the ability to recognize un use emotions constructively. In this study as an important fact was noted that socio-emotional health is multidimensional and includes positive mental health structures, for example, life satisfaction (Snowden et al., 2015). Socio-emotional encompass number of interrelated areas, including 
social interaction, emotional awareness, and ability of self-regulation. Social interaction focuses on the relationships we share with others, building relationships with peers and adults. As the child develops socially, he learns to take responsibility, help, and cooperate with others. Emotional awareness includes the ability to recognize and understand one's emotions and feelings, a person learns to understand how his behavior and emotions affect him and the people around him. Self-regulation is the ability to express one's feelings, thoughts and behave in a socially appropriate way (Damon et al., 2015).

One of the researchers of positive psychology - Martin Seligman, was the one who started to change the focus from developmental disorders to personality strengths. He recommends focusing on a person's social and emotional health through strengths and that, what makes life meaningful (Boman et al., 2017). Based on these recommendations, $M$. J. Furlong has conducted a study on the socio-emotional health of adolescents and young people in the United States, which showed that $15-20 \%$ of young people have problems with social and emotional health. In 2014. M. J. Furlong together with his research group developed a Social Emotional Health Survey (SEHS). This survey measures the four constructs that make up social-emotional health and the total SEH factor that encompasses all four components (Boman et al., 2017). The basic principle of SEHS is that flourishing development is partly based on the living conditions of young people, which promote the disposition of inner cognition or form their own schemes related to belief in self, belief in others, emotional competences and engaged living. These factors contribute to an upward spiral in the formation of relationships between young people and peers, and consolidate developmental theories (Furlong et al., 2015).

The first construct of the SEHS model is belief in self, which consists of three constructs studied in social-emotional learning (Furlong et al., 2014). Selfefficacy, which is a person's confidence in his/her abilities of controlling his/her activities and environmental requirements. Persistence, which is a course of action with a long-term goal, including working with challenges, not to lose interest over the years, despite failures and obstacles to achieving the goal. Belief in self - the ability to understand one's strengths and weaknesses, understanding one's emotions, reactions, and motivation (Renshaw et al., 2018).

As a second construct of the model of social-emotional health, there is belief in others (Furlong et al., 2014), which includes family support, school support and peer support. These components are social exchange processes between family, teachers, and peers. It contributes to the behavioral development model, the development of social cognition and the development of the value system (Renshaw et al., 2018). 
Čukna et al., 2021. Relevance of Indicators of Social Emotional Health in Different Samples of Adolescence

The third construct of the model is the emotional competence, which consists of the three lower order constructs (Furlong et al., 2014). Emotional selfregulation, which is the ability to express emotions according to the current situation. It is the ability to accept and feel different emotions and react flexibly to them. Empathy is the ability to notice and feel other people's emotions. Selfcontrol is an ability that begins to develop in infancy. A person learns to respond appropriately to various life situations (Renshaw et al., 2018).

The last of the construct of the social-emotional health model is engaged living, which includes three other subordinate constructs (Furlong et al., 2014). Gratitude, which is like a sense of gratitude that arises from responding and receiving any kind of personal benefit. Passion or zeal is the ability to do things with enthusiasm and confidence. Optimism is inherent in a person who is characterized by resilience and faith in the future (Renshaw et al., 2018).

These four adapted scales can be described in terms of content as psychological construct, which M. J. Furlongs are defined as socio-emotional health factors. It is concluded that each indicator described by the above construct can be named in the context of the basic element of positive psychology - wellbeing, the effect is enhanced when they are combined with other features (Furlong et al., 2014). Other features may include adjustment programs or interventions, socio-economic status of the family, overall life satisfaction component, education, and other indicators (Snowden et al., 2015).

The Social Emotional Health Survey (SEHS-C) has been translated into several languages and data is currently being collected from adolescents living in Australia, Japan, Korea, Turkey, Malta, Lithuania, and Latvia (Renshaw et al., 2018). Analyze have been conducted to find out how the results obtained by students in the SEHS-C survey are related to the results that are important for educators and parents. Researchers at the University of California, Santa Barbara and around the world have conducted a number of studies that confirm that the test has a constructive validity, it measures what it is intended for. This test can be used and interpreted in the same way for all adolescents, regardless of age, gender, and race. Correlations between higher scores in social-emotional health and students' subjective well-being and negative correlations between socialemotional health and psychological suffering have been observed (Furlong et al., 2014).

The first study using a social-emotional health survey was conducted in 2013. It tested the reliability of the test. The study involved 4189 California 8.-12. form students. The results, when assessing the differences, showed that girls had higher scores on the scales related to belief in others and on the scales of emotional competence. Boys scored higher on a scale that measures belief in self. The study found that the SEH factor was associated with higher academic achievement and perceptions of school safety, but a low SEH factor was associated with a higher 
chance of use of addictive substances and depression symptoms. Overall, preliminary results provide psychometric evidence that the SEHS-C theory model is able to multi-dimensionally measure socio-emotional health construct (Renshaw et al., 2018).

As adolescents and young people are one of the most sensitive age groups, the authors of this article also decided to focus on this topic, based on the topicality in world research. Studies show that adolescents aged 12-18 have a high socioemotional health rate of $38 \%$, but a low $6 \%$ of young people (Piquers et al., 2017).

\section{Topicality of Adolescence in Modern Psychology Research}

Historically, adolescence is believed to begin with puberty and end with the transition to adulthood, which is marked by family formation and married life. Today, however, these boundaries cannot be so strictly separated, and this often involves accepting other roles and responsibilities of adults, such as entering employment, financial independence, and partnership. These events today take place at different ages, in different parts of the world, as a result of which the concept of adolescents tends to be defined differently (Patton et al., 2018). The World Health Organization determines the adolescence from 10 to 24 years of age, resulting in the additional concept of a young person. This broad age group is divided into smaller ones: early adolescent or adolescent from 10 to 14 years of age, late adolescent or young person from 15 to 19 years of age and young adult from 20 to 24 years of age (Patton et al., 2018). Psychological and psychiatric research has reported that negative emotions, such as anxiety, unrest, and stress, are associated with adverse health outcomes, poor academic performance, and behavioral problems that include use of intoxicants and risky sexual behavior. Research on emotional well-being reveals that positive emotions, such as joy, interest in life, emotional competencies, predict positive mental health development, and promote positive thinking (Wang et al., 2018). Developmental neurologist Ron Dahl has described the adolescent age as a phase of passion, during which positive processes, meaningful fascination for additional activities promotes positive development of social and emotional health in adulthood. However, the development of antisocial behavior, violence, drug use, extreme activities hinder the development of the individual and contribute to the harm of the wider society. Lack of social and emotional competencies contributes to the development of mental disorders, including depression (Patton et al., 2018).

The young age group from 15 to 19 years is characterized by puberty, especially for boys. During this time, the brain continues to be extremely active in terms of development. Young people continue to develop self-regulatory skills, leading to future orientation and greater ability to assess the short- and long-term consequences of their decisions (Meeus et al., 2015). The influence of the family 
Čukna et al., 2021. Relevance of Indicators of Social Emotional Health in Different

Samples of Adolescence

at this stage of life becomes different, as many of the young people have a degree of autonomy, although they continue to live with their parents. Education is also important at this age (Patton et al., 2018). The age of young people can be both exciting and mind blowing. This includes the formal years in which individuals reach sexual maturity and develop the social, emotional, and cognitive skills needed for individuals to move towards independence and adulthood (Walkere et al., 2017).

\section{Socio-emotional Health of Young People in the Context of Various Socio-demographic Indicators}

Today, a small part of researchers focusing on mental health research study the relationship with environmental impacts as well. Young people in rural areas may have different family and peer influences than young people living in cities. Various factors can affect a young person's social and emotional health during adolescence. For example, for young people in rural areas, the overlap of the social environment in the family and society is often seen as a protective factor that can contribute to the positive development of young people. However, limited employment opportunities in rural areas create disadvantages for young people. As young people move into adulthood, these low job opportunities in rural areas and the desired higher education increase the chances that young people from rural areas will have to move to the city to achieve their educational and career goals. These impending changes may leave young people with feelings of uncertainty, anxiety or stress (Wang et al., 2018).

A 2018 study on the emotional health of adolescents found that negative parent-child relationships and family economic difficulties could contribute to the negative emotional state of rural youth. As well as bulling or various types of aggression among young people promote negative emotional health among rural youth. However, other factors in the context of the rural environment are seen as protective, such as a favorable environment and school climate can be a reason for a teenager to feel positive. However, the use of harmful substances was an important factor in promoting negative emotional health in both rural and urban environments (Wang et al., 2018).

As an additional factor, the study on the impact of the rural environment on adolescents also analyzed gender differences. In general, it was concluded that boys and girls have different emotional health profiles: women are more likely to suffer from depressive and anxiety symptoms, while men are more likely to suffer from antisocial behavior problems. Compared to girls living in cities, rural girls were more likely to show negative emotional health. Previous research has found that girls' negative emotional health can contribute to behavioral problems, more frequent eating disorders and self-harming behaviors (Wang et al., 2018). 
Understanding and identifying changes in social and emotional health among young people and adolescents can contribute to timely and effective intervention. It can be useful for families and schools in rural areas with fewer mental health professionals, and for young people who may face difficult decisions when planning the future (Wang et al., 2018).

\section{Method of Study}

\section{Procedure}

The primary data of the study were collected in September 2019 in several general education schools, in coordination with parents and school management, as well as secondary data from previous research on this topic in Latvia, organized under the guidance Professor Guna Svence University of Latvia for several years (Timofejeva, 2014; Knnaze, 2015; Pētersone, 2018; Čukna, 2018). A sample of more than 500 students was formed for this study $(\mathrm{N}=593)$.

\section{Sample}

From the total sample $(\mathrm{N}=593)$, 318 were adolescents (mean age $\mathrm{M}=13.01$, $\mathrm{SD}=.84$ ) participated in the study, of which were 151 boys and were 167 girls, and were 274 young people (mean age $M=15.85, S D=1.02$ ); of which were 132 boys and were 142 girls. There were 184 Russian-speaking respondents, of whom 78 were adolescents (mean age $\mathrm{M}=12.91, \mathrm{SD}=.76$ ), of whom 44 were boys and were 34 girls, and 106 were young people (mean age $M=16.25$, $S D=1.09$ ), of which 44 boys and 62 girls.

\section{Characteristics of socio-demographic indicators}

As several socio-demographic indicators were used in the study. In Table 1 the breakdown by them is made, using references to authors who have involved similar socio-demographic indicators in youth group studies.

Table 1 Distribution of Socio-demographic Differences

\begin{tabular}{|c|c|c|}
\hline Comparison criteria & Sample & Reference \\
\hline \multirow{2}{*}{$\begin{array}{l}\text { Gender differences } \\
\qquad(\mathrm{n}=593)\end{array}$} & Male $\left(n_{3}\right)=283$ & \multirow{2}{*}{$\begin{array}{c}\text { Guo, Tomson, Keller, Soderqvist, \& } \\
2018 \\
\text { Patton, Sawyer, Santelli, Ross, \& Afifi } \\
2018\end{array}$} \\
\hline & Female $\left(\mathrm{n}_{4}=310\right)$ & \\
\hline \multirow{2}{*}{$\begin{array}{l}\text { Age differences } \\
\left(\mathrm{n}_{1}=409\right)\end{array}$} & Adolescents $\left(\mathrm{n}_{7}=241\right)$ & \multirow{2}{*}{$\begin{array}{l}\text { Walkere, Bell, Flores, Gulley, Willing, } \\
\text { \& Paul, } 2017\end{array}$} \\
\hline & Young people $\left(\mathrm{n}_{8}=168\right)$ & \\
\hline \multirow{2}{*}{$\begin{array}{l}\text { Nationality differences } \\
(\mathrm{n}=593)\end{array}$} & Latvians $\left(\mathrm{n}_{1}=409\right)$ & \multirow{2}{*}{ Smith,You, Shimoda, \& Furlong, 2015} \\
\hline & Minority $\left(\mathrm{n}_{2}=184\right)$ & \\
\hline \multirow{2}{*}{$\begin{array}{l}\text { Environmental } \\
\text { differences } \\
\left(\mathrm{n}_{1}=409\right)\end{array}$} & Urban schools $\left(\mathrm{n}_{5}=188\right)$ & \multirow{2}{*}{$\begin{array}{l}\text { Wang, Hegedorn, McLaughlin, \& Bary, } \\
2018\end{array}$} \\
\hline & Rural schools $\left(\mathrm{n}_{6}=221\right)$ & \\
\hline
\end{tabular}


Čukna et al., 2021. Relevance of Indicators of Social Emotional Health in Different

Samples of Adolescence

\section{Method}

To measure the positive aspects of young people's mental health, the Social Emotional Health Survey - Secondary (SEHS-S) (Furlong, You, Renshaw, \& O'Malley, 2014; adaptation in Latvian by Knnaze, 2015; adaptation in Russian by Timofẽjeva, 2014). The Social Emotional Health Survey consists of 12 separate modules of positive psychology health resources, which are combined in 4 mental health latent modules: emotional competence (empathy, self-control, selfregulation of emotions), engaged living (gratitude, enthusiasm, optimism), belief in self (persistence, self-awareness, self-efficacy), belief in others (school support, peer support, family support), which in turn form a meta - construct Covitality or SEH (socio-emotional health) factor. The survey consists of 36 statements, which are evaluated on the Likert scale. Questions 1 to 30 should be answered on a Likert scale of 1 (not for me) to 4 (completely for me). In turn, questions 31 to 36 should be answered according to the Likert scale from 1 (I do not feel/I'm not) to 5 (I feel/ I really am). In Latvia, the internal coherence indicators obtained in the adaptation process were as follows: the total internal coherence indicator $\alpha=.85$. In the subscales, the Cronbach's alpha coefficients are: belief in self $\alpha=.73$; belief in others $\alpha=.72$; emotional competence $\alpha=.41$; engaged living $\alpha=.84$.

Due to unacceptable Cronbach's alpha for emotional competence scale $(\alpha=.41)$, the translation of articles on this scale was clarified in this study. After the changes, the internal coherence indicator in the mentioned sub-scale improved to $\alpha=.76$. Thus, the Cronbach's alpha scores in this study were as follows: total $\alpha=0.90$, belief in self $\alpha=.73$, belief in others $\alpha=.78$, engaged living $\alpha=.87$, and sense of emotional competence $\alpha=.72$.

SPSS program version 22.00 was used for data processing and analysis. Cronbach's alpha, reaction indices, and discrimination indices were calculated for the coherence of the surveys. Differences between different groups of adolescents and young people were calculated using the Mann-Whitney criterion. Correlations between different groups of adolescents were calculated using Spearman's correlation analysis.

\section{Results}

In order to answer the main research question - which of the sociodemographic factors - gender, age, nationality or environment, could more precisely predict the indicators of SEH factor, a multiple regression analysis was performed (Table 2). In this model, the SEH factor was included as a dependent variable, and gender, age, nationality and environment (rural or urban school) were included as independent variables. 
Table 2 Standard Multiple Regression Analysis of the Dependent Variable SEH Factor with the Independent Variables - Gender, Age, Nationality, and Environment

\begin{tabular}{lccc}
\hline Independent variables & $\boldsymbol{B}$ & $\boldsymbol{S E} \boldsymbol{B}$ & $\boldsymbol{\beta}$ \\
\hline Step 1 & & & .07 \\
Gender & 2.31 & 1.31 & -.07 \\
Nationality & -2.46 & 1.67 & -.04 \\
Age group & -1.19 & 1.33 & $-.19^{* *}$ \\
Environment & -6.17 & 1.59 & .07 \\
\hline Step 2 & & & -.08 \\
Gender & 2.32 & 1.31 & $-.19^{* *}$ \\
Nationality & -2.72 & 1.65 & .07 \\
Environment & -6.27 & 1.59 & $-.15^{* *}$ \\
\hline Step 3 & & & \\
Gender & 2.23 & 1.31 & \\
Environment & -4.92 & 1.36 & \\
\hline Note. $N=593$. Step $1 R^{2}=.03, p<.01 ;$ Step $2 R^{2}=.03, p<.01 ;$ Step $3 \mathrm{R}^{2}=.03, p<.01 ;$ \\
$* * p<.01$. & & &
\end{tabular}

Looking at the results obtained in the regression model on the SEH factor and the relationship between gender, age, nationality and environment (Table 2), it can be seen that the variables included in the first step - gender, nationality and age group - are not statistically significant in explaining the SEH factor variation. In turn, the environment (urban or rural school where the student studies) is statistically significant $(\beta=-.19, \mathrm{p}<.01)$ and explain the variation of the SEH factor $(\mathrm{R} 2=.03, \mathrm{~F}(4,589)=4.71, \mathrm{p}<.01)$.

When performing the second step of the regression analysis, subtracting the gender, the environment also remains a statistically significant variable $(\beta=-.19$, $\mathrm{p}<.01)$ in explaining the variation of the SEH factor $(\mathrm{R} 2=.03, \mathrm{~F}(3,589)=6.01$, $\mathrm{p}<.01)$.

In the third step, removing the nationality, the environment also remains a statistically significant variable $(\beta=-.19, \mathrm{p}<.01)$ in explaining the variation of the SEH factor $(\mathrm{R} 2=.03, \mathrm{~F}(2,589)=7.65, \mathrm{p}<.01)$. This model is generally statistically significant and explains $3 \%$ of respondents' variation in the total SEH factor.

\section{Discussion}

The study concluded that the environment (urban or rural school) is a statistically significant indicator in predicting SEH. Examining the data in more detail, it was found that respondents who study in urban schools show statistically higher results on the belief in self scale and that the substructure self-efficacy and persistance of this scale have higher results in this sample compared to 
Čukna et al., 2021. Relevance of Indicators of Social Emotional Health in Different

Samples of Adolescence

respondents who study in small, rural schools. According to research (Wanget al., 2018) young people in rural areas may have different family and peer impacts than young people living in cities, and limited job opportunities in rural areas put young people at a disadvantage, and the expected changes after leaving school may leave them feeling insecure, anxious, or stressed.

The calculated results on the engaged living scale and the optimism, gratitude and enthusiasm sub-constructs of this scale show that respondents who study in urban schools show statistically higher results compared to respondents who study in small, rural schools. The total SEH factor indicator shows statistically higher results for urban school students compared to rural school students. This is partly consistent with a 2018 study (Wang et al., 2018) on adolescent emotional health, which found that negative parent-child relationships and family economic difficulties could contribute to the negative emotional state of rural youth. Performing an additional regression analysis led to the conclusion that the environment in which the student learns is important in explaining the overall SEH factor. The obtained data were the most statistically significant when analyzing all other used socio-demographic indicators. These results are also confirmed by a 2018 study on positive mental health in Chinese adolescents, which concluded that important determinants of health are factors related to the school environment, such as peer relationships and teacher support, education, family income, employment and living environment that can positively predict the development of mental health (Guo et al., 2018).

Limitations of the study - the survey was conducted only in one city and one small town district, which calls attention to the fact that if the study area were expanded, the conclusions that could be drawn about the differences between urban and rural adolescents and young people would be more reliable and complete. It is possible that repeating the study in other areas would lead to different results. However, it shows the potential of the idea of this study.

\section{References}

Belkin, G., Wissow, L., Lund, C., Aber, L., \& Bhutta, Z. (2017). Converging on child mental health - toward shared global action for child development. PMC PubMed Central, 4 (20). Retrieved from https://www.ncbi.nlm.nih.gov/pmc/articles/PMC5719480/

Boman, P., Mergler, A., \& Pennell, D. (2017). The Effects of Covitality on Well-Being and Depression in Australian High School Adolescents, 3 (2-15). https://doi.org/10.21767/ 2471-9854.100046

Bratton, S. C., Landreth, G. L., Kellam, T., \& Blackard, T. (2019). Child-Teacher Relationship Training as a Head Start Early Mental Health Intervention for Children Exhibiting Disruptive Behavior. PsycARTICLES, 28 (1). Retrieved from http://datubazes.lanet.lv: 3537/ehost/detail/detail

Damon, E.J, Greenberg, M., \& Crowly, M. (2015). Early Social-Emotional Functioning and Public Health: The Relationship Between Kindergarten Social Competence and Future 
Wellness. American Journal of Public Health, 105 (11). Retrieved from https://ajph.aphapublications.org/doi/full/10.2105/AJPH.2015.302630

Furlong, M.J., Dowdy, E., Moore, S.A. \& Bertone, A. (2015). Validation of the social and emotional health survey for five sociocultural groups: multi group invariance and latent mean analyses. Psychology in the Schools, 52(4). https://doi.org/10.1002/pits.21828

Furlong, M.J., Dowdy, E., Moore, S.A., \& Bertone, A. (2018). Assessment of complete social emotional wellness: An international school psychology perspective. In C. Hatzichristou \& B. Nastasi (Eds.), Handbook of school psychology in a global context. Dordrecht, Netherlands: Springer.

Furlong, M.J., Renshaw, T.L., Dowdy, E., \& Rebelez, J. (2014). Covitality: A synergistic conception of youths' mental health. In M. J. Furlong, R. Gilman, \& E. S. Huebner (Eds.), Handbook of Positive Psychology in the Schools (2nd ed.). New York, NY: Routledge/Taylor \& Francis.

Guo, C., Tomson, G., Keller, C., \& Söderqvist, F. (2018). Prevalence and correlates of positive mental health in Chinese adolescents. BMC Public Health, 18(1), 1-11. https://doi.org/10.1186/s12889-018-5133-2

Meeus, W., Van de Schoot, R., Hawk, S. T., Hale, W. W., \& Branje, S. (2016). Direct aggression and generalized anxiety in adolescence: heterogeneity in development and intra-individual change. Journal of Youth and Adolescence, 45(2), 361-375. https://doi.org/10.1007/s10964-015-0388-8

Patton, G. C., Sawyer, S. M., Santelli, J. S., Ross, D. A., Afifi, R., Allen, N. B., ... \& Viner, R. M. (2016). Our future: a Lancet commission on adolescent health and wellbeing. The Lancet, 387(10036), 2423-2478. https://doi.org/10.1016/S0140-6736(16)00579-1

Piquers, J. A., Garcia-Olcina, M., Rivera-Riquelme, M., Rodriguez-Jimenez, T., MartinezGonzalez, A. E., \& Cuijpers, P. (2017). DetectaWeb Project: Study protocol of a webbased detection of mental health of children and adolescents. BMJ Open, 7(10), e017218. https://doi.org/10.1136/bmjopen-2017-017218

Renshaw, T.R., Furlong, M.J., Dowdy, E., \& Rebelez, J. (2014). Covitality: A synergistic conception of youths' mental health. In M. J. Furlong, R. Gilman, \& E. S. Huebner (Eds.), Handbook of Positive Psychology in the Schools (2nd ed.). New York, NY: Routledge/Taylor \& Francis. Retrieved from https://www.researchgate.net/ publication/263619629

Renshaw, T.R., Furlong, M.J., Dowdy, E., \& Rebelez, J. (2018). Social Emotional Health Survey-Secondary - 2015 edition. Santa Barbara, CA: University of California Santa Barbara, International Center for School Based Youth Development.

Snowden, M. B., Steinman, L. E., Carlson, W. L., Mochan, K. N., Abraido-Lanza, A. F., Bryant, L. L., ... \& Anderson, L. A. (2015). Effect of physical activity, social support, and skills training on late-life emotional health: a systematic literature review and implications for public health research. Frontiers in Public Health, 2, 213. http://doi.org/ 10.3389/fpubh.2014.00213

Thomson, K. C., Guhn, M., Richardson, C. G., Ark, T. K., \& Shoveller, J. (2017). Profiles of children's social-emotional health at school entry and associated income, gender and language inequalities: a cross-sectional population-based study in British Columbia, Canada. BMJ Open, 7(7), e015353. https://doi.org/10.1136/bmjopen-2016-015353

Timofējeva, T. (2016). Theoretical and practical research of M. J. Furlong concept of socioemotional health in adolescents and young adults. LU data base. Retrieved from https://dspace.lu.lv/dspace/handle/7/43679 
Čukna et al., 2021. Relevance of Indicators of Social Emotional Health in Different

Samples of Adolescence

Walker, D. M., Bell, M. R., Flores, C., Gulley, J. M., Willing, J., \& Paul, M. J. (2017). Adolescence and reward: making sense of neural and behavioral changes amid the chaos. Journal of Neuroscience, 37(45), 10855-10866. https://doi.org/10.1523/JNEUROSCI. 1834-17.2017

Wang, D., Hagedorn, A. D., McLaughlin, D. K., \& Bray, B. C. (2018). Change and Stability of Emotional Health of Rural Pennsylvania Youth During High School. The Journal of Rural Health, 34(3), 322-332. https://doi.org/10.1111/jrh.12296 